\title{
A Comparative Stability Analysis of Atlantic and Pacific Niño Modes*
}

\author{
JoKe F. LÜBBecKe AND Michael J. MCPHADEN
}

NOAA/PMEL, Seattle, Washington

(Manuscript received 24 October 2012, in final form 11 February 2013)

\begin{abstract}
El Niño-Southern Oscillation (ENSO) in the Pacific and the analogous Atlantic Niño mode are generated by processes involving coupled ocean-atmosphere interactions known as the Bjerknes feedback. It has been argued that the Atlantic Niño mode is more strongly damped than ENSO, which is presumed to be closer to neutrally stable. In this study the stability of ENSO and the Atlantic Niño mode is compared via an analysis of the Bjerknes stability index. This index is based on recharge oscillator theory and can be interpreted as the growth rate for coupled modes of ocean-atmosphere variability. Using observational data, an ocean reanalysis product, and output from an ocean general circulation model, the individual terms of the Bjerknes index are calculated for the first time for the Atlantic and then compared to results for the Pacific. Positive thermocline feedbacks in response to wind stress forcing favor anomaly growth in both basins, but they are twice as large in the Pacific compared to the Atlantic. Thermocline feedback is related to the fetch of the zonal winds, which is much greater in the equatorial Pacific than in the equatorial Atlantic due to larger basin size. Negative feedbacks are dominated by thermal damping of sea surface temperature anomalies in both basins. Overall, it is found that both ENSO and the Atlantic Niño mode are damped oscillators, but the Atlantic is more strongly damped than the Pacific primarily because of the weaker thermocline feedback.
\end{abstract}

\section{Introduction}

Tropical sea surface temperature (SST) variability on interannual time scales is of interest owing to its impact on rainfall variability over adjacent land regions and the associated socioeconomic impacts (e.g., Xie and Carton 2004). It is thus important to understand the processes that control the strength and frequency of these SST anomalies. The globally dominant mode of variability on interannual time scales is the Pacific El Niño-Southern Oscillation (ENSO) (McPhaden et al. 2006). ENSO has received a lot of attention because it is so prominent and its stability and associated ocean-atmosphere feedbacks have been discussed extensively in the literature [for a review see, e.g., Sarachik and Cane (2010)]. There is, however, also a climate mode on interannual time scales in the tropical Atlantic, the so-called Atlantic zonal mode

\footnotetext{
* Pacific Marine Environmental Laboratory Contribution Number 3947.

Corresponding author address: Joke F. Lübbecke, NOAA/PMEL, 7600 Sand Point Way NE, Seattle, WA 98115.

E-mail: joke.luebbecke@noaa.gov
}

or Atlantic Niño mode [see, e.g., Chang et al. (2006) for a review of the tropical Atlantic climate modes], which is focused in the cold tongue region of the eastern tropical Atlantic and along the southwestern African coast (Fig. 1b). The Atlantic Niño mode plays an important role in the onset of the West African monsoon (Brandt et al. 2011) while SST variability in the southeastern tropical Atlantic is related to rainfall anomalies (Reason and Rouault 2006) and to effects on the marine ecosystem along the West African coast (Binet et al. 2001). Warmest temperatures in the tropical Atlantic are on average found in the western basin and to the north of the equator coincident with the position of the intertropical convergence zone (ITCZ, Fig. 1a). The wind field is dominated by the convergence of the northeasterly and southeasterly trade winds just north of the equator.

On interannual time scales, the Atlantic Niño mode is governed by feedbacks involving ocean dynamics and ocean-atmosphere interactions very similar to those that sustain ENSO in the tropical Pacific: A warm anomaly in the eastern equatorial basin results in a relaxation of the trade winds to its west, which leads to reduced upwelling and a deepening of the thermocline in the east that causes further warming (Carton and Huang 1994). Tendencies for cold events are opposite to 

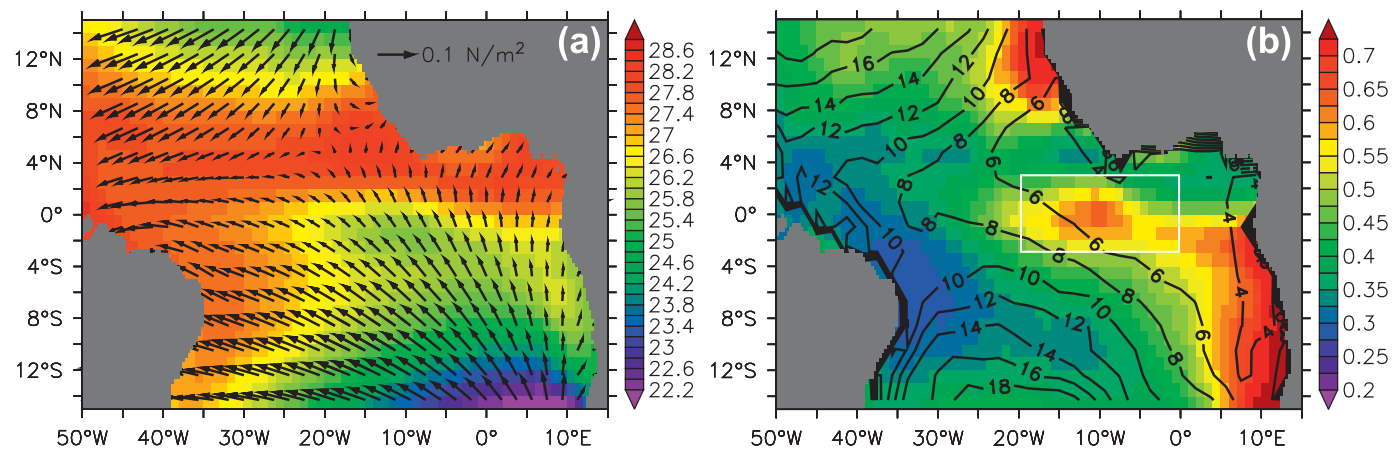

FIG. 1. (a) Mean Reynolds SST $\left({ }^{\circ} \mathrm{C}\right)$ and NCEP-NCAR wind stress $\left(\mathrm{N} \mathrm{m}^{-2}\right)$ and (b) standard deviation of interannual SST (color shading) and wind stress $(\times 1000)$ anomalies (contours) in the tropical Atlantic (1982-2010); white box indicates the Atl 3 region $\left(3^{\circ} \mathrm{S}-3^{\circ} \mathrm{N}, 20^{\circ} \mathrm{W}-0^{\circ}\right)$.

those for warm events. Collectively, these processes are referred to as the Bjerknes feedback (Bjerknes 1969).

There are, however, significant differences between El Niño and La Niña in the Pacific and Atlantic Niño and Niña events. The Pacific Niño is, in general, stronger and longer lived than its Atlantic counterpart. In addition, the Atlantic Niño mode appears to be more strongly damped and not self-sustained (Zebiak 1993) compared to the Pacific, which has been argued to be closer to neutrally stable (Fedorov and Philander 2000). Several studies suggest that external forcing associated with ENSO helps to maintain the otherwise damped interannual variations in the tropical Atlantic (Nobre et al. 2003; Illig and Dewitte 2006). Keenlyside and Latif (2007) showed that all three elements of the Bjerknes feedback exist in the Atlantic but are weaker than in the Pacific, resulting in a 50\% lower growth rate for anomalies. From a statistical analysis of observations as well as a conceptual recharge oscillator model Jansen et al. (2009) also found that Bjerknes feedbacks are active in the Atlantic but more strongly damped than in the Pacific. As pointed out by Chang et al. (2006), whether the feedback can sustain itself depends on the strength of the subsurface ocean response and the connection between subsurface and surface.

Based on the recharge oscillator framework for ENSO, Jin et al. (2006) developed a stability index for ocean-atmosphere interactions in the tropical Pacific. This so-called Bjerknes index is derived from an areaaveraged form of the linear equation for SST anomalies. It is a measure for the stability of the coupled ENSO mode and can be interpreted as the growth rate of the recharge oscillator. The Bjerknes index has been used to assess the coupled stability of ENSO in various models (Kim and Jin 2011a,b) and to investigate the seasonal cycle in ENSO growth rate (Stein et al. 2010) but has not been applied to the Atlantic Niño mode yet. Since the main feedbacks are the same and it has been shown that the Atlantic Niño mode is dominated by recharge oscillator dynamics similar to those of ENSO (Ding et al. 2010), the Bjerknes index can be applied to the Atlantic as well.

In this study we will investigate the stability of the Atlantic Niño mode in terms of the Bjerknes stability index. This will offer new insights into the relative importance of the factors that control Atlantic Niño mode variability. We will check how consistent these results are among different datasets and compare them to results for the Pacific ENSO mode using output from model simulations. This will help us better understand the differences between the Pacific and Atlantic Niño modes.

The remainder of this paper is organized as follows. In section 2, we derive the Bjerknes index following the formulation of Jin et al. (2006). Then the observational data and model output used in this study as well as the method to calculate the terms are briefly described in section 3 . Section 4 presents the results for the tropical Atlantic, which are compared to Pacific results in section 5. In section 6 the results are summarized and their implications are discussed.

\section{BJ index formulation}

The Bjerknes coupled stability index has been derived by Jin et al. (2006) starting from the linear equation for SST anomalies in the mixed layer:

$$
\frac{\partial T}{\partial t}=-\left(\bar{u} \frac{\partial T}{\partial x}+\bar{v} \frac{\partial T}{\partial y}+\bar{w} \frac{\partial T}{\partial z}+u \frac{\partial \bar{T}}{\partial x}+v \frac{\partial \bar{T}}{\partial y}+w \frac{\partial \bar{T}}{\partial z}\right)+Q,
$$

where $T$ represents the sea surface temperature anomalies; $u, v$, and $w$ are the zonal, meridional, and vertical velocity anomalies; and $Q$ represents the net anomalous heat flux and diffusion. The overbar indicates the climatological time mean of a particular variable. 
Next, a volume average is taken over the area of maximum interannual SST anomalies, that is, the eastern equatorial region, and from the ocean surface to the mixed layer depth:

$$
\begin{aligned}
\frac{\partial\langle T\rangle_{E}}{\partial t} \approx & -\left(\frac{\langle\bar{u}\rangle_{E}}{L_{x}}+\frac{\langle-2 y \bar{v}\rangle_{E}}{L_{y}^{2}}+\frac{\langle\bar{w}\rangle_{E}}{H_{m}}\right)\langle T\rangle_{E} \\
& -\langle u\rangle_{E}\left\langle\frac{\partial \bar{T}}{\partial x}\right\rangle_{E}+\langle H(\bar{w}) \bar{w}\rangle_{E} \frac{T_{\text {sub }}}{H_{m}} \\
& -\langle w\rangle_{E}\left\langle H(\bar{w}) \frac{\partial \bar{T}}{\partial z}\right\rangle_{E}+\langle Q\rangle_{E},
\end{aligned}
$$

where $\langle\cdot\rangle_{E}$ denotes the volume average, $L_{x}$ and $L_{y}$ are the zonal and meridional extent of the eastern equatorial box, and $y$ is the distance from the equator. The factor $-2 y / L_{y}$ comes from the assumption that the structure of the SST anomalies is Gaussian-like with an $e$-folding decay scale of $L_{y}$. The step function $H(x)$ ensures that only upstream vertical advection is taken into account. The depth $H_{m}$ represents the effective depth for vertical advection and $T_{\text {sub }}$ the subsurface temperature.

Then balance equations from approximations used to derive the recharge oscillator model (Jin 1997) are applied in order to write the rhs of Eq. (2) as a linear function of eastern equatorial SST anomalies $T$ and zonally averaged thermocline depth or heat content anomalies $h$ as shown in detail in Jin et al. (2006), Stein et al. (2010), and Kim and Jin (2011a). The balance equations will be discussed in the next section when the regression values are estimated for the Atlantic. The equation then reads [following Jin et al. (2006) with some modifications from Kim and Jin (2011a,b) and Stein et al. (2010)] as

$$
\frac{\partial\langle T\rangle_{E}}{\partial t}=2 I_{\mathrm{BJ}}\langle T\rangle_{E}+F[h],
$$

where

$$
\begin{aligned}
2 I_{\mathrm{BJ}}= & -\left(\frac{\langle\bar{u}\rangle_{E}}{L_{x}}+\frac{\langle-2 y \bar{v}\rangle_{E}}{L_{y}^{2}}+\frac{\langle\bar{w}\rangle_{E}}{H_{m}}\right)-\alpha \\
& +\mu_{a} \beta_{u}\left\langle-\frac{\partial \bar{T}}{\partial x}\right\rangle_{E}+\mu_{a} \beta_{w}\left\langle-\frac{\partial \bar{T}}{\partial z}\right\rangle_{E} \\
& +\mu_{a} \beta_{h}\left\langle\frac{H(\bar{w}) \bar{w}}{H_{m}} a_{h}\right\rangle_{E}
\end{aligned}
$$

and

$$
F=\beta_{u h}\left\langle-\frac{\partial \bar{T}}{\partial x}\right\rangle+\left\langle\frac{H(\bar{w}) \bar{w}}{H_{m}}\right\rangle_{E} a_{h},
$$

where $\alpha$ represents the thermal damping, $\mu_{a}$ describes the wind response to SST forcing, $\beta_{u}$ is the ocean surface zonal current response to wind forcing, and $\beta_{u h}$ denotes the geostrophic adjustment of zonal currents to thermocline depth variations. The $\beta_{w}$ and $\beta_{h}$ describe the upwelling and thermocline slope response to wind forcing, respectively, and $a_{h}$ represents the effect of thermocline depth changes on subsurface temperature.

The Bjerknes coupled stability index (or BJ index) is represented as $I_{\mathrm{BJ}}$. It corresponds to the growth rate of the recharge oscillator while $F[h]$ is associated with the recharge/discharge phase transition of heat content. The terms of the BJ index [Eq. (4)] describe either damping or enhancement of a SST anomaly in the eastern equatorial basin. From left to right they correspond to mean advection and thermal damping that make negative contributions, and zonal advection, Ekman, and thermocline feedbacks that make positive contributions. A negative BJ index is associated with a damped system, while a positive index indicates that the coupled system is unstable and potentially a self-sustained oscillator. We first calculate the individual terms for the tropical Atlantic in order to assess the stability of the Atlantic Niño mode and then compare them to their Pacific counterparts. The regression coefficients $\alpha, \mu_{a}, \beta_{u}, \beta_{u h}, \beta_{w}, \beta_{h}$, and $a_{h}$ are explained in more detail in the subsections on the individual terms.

\section{Data and methodology}

Fields of tropical Atlantic Ocean temperature, ocean velocity, zonal wind stress, and heat flux are taken from observational datasets and reanalysis products as well as from output of numerical ocean model simulations. The same ocean model simulations are used for the Pacific. All time series are detrended prior to further analysis. We computed interannual anomalies by subtracting a mean seasonal cycle from the full time series.

As observational datasets for the tropical Atlantic, we use monthly NOAA Optimum Interpolation SST (or Reynolds SST) (Reynolds et al. 2002) consisting of a blend of satellite and in situ observations with a spatial resolution of $1^{\circ}$, available from December 1981 to present. Although observations of subsurface temperature are sparse in the tropical Atlantic, subsurface temperature and thermocline depth are available from the expendablebathythermograph-derived monthly Tropical Atlantic Ocean Subsurface Temperature Atlas (TAOSTA) dataset by Vauclair and du Penhoat (2001) for the time period 1979-99 with $2^{\circ}$ spatial resolution. For ocean currents we use 15-m depth velocity from the Lumpkin and Garzoli (2005) drifter climatology with a spatial resolution of $1^{\circ}$. We also use Ocean Surface Currents 
Analyses-Real time (OSCAR) ocean currents, a product constructed from satellite sea surface height ( $\mathrm{SSH}$ ), scatterometer winds, and SST that is designed to represent the average flow in the upper $30 \mathrm{~m}$. OSCAR is available at $13^{\circ}$ horizontal resolution for 1993-2011 (Bonjean and Lagerloef 2002; see http://www.oscar. noaa.gov). Monthly heat flux data are taken from TropFlux, available for 1979-2010 at $1^{\circ}$ horizontal resolution since this product performs well compared to tropical moored buoy array data (Praveen Kumar et al. 2012). We also use surface heat flux from the 40-yr European Centre for Medium-Range Weather Forecasts Re-Analysis (ERA-40) (Uppala et al. 2005) for 19582001 with a spatial resolution of $2.5^{\circ}$. These datasets are complemented by monthly zonal wind stress from the National Centers for Environmental Prediction (NCEP)National Center for Atmospheric Research (NCAR) reanalysis (Kalney et al. 1996) for 1958-2000 at $2^{\circ}$ horizontal resolution.

Not all of the variables that are needed to calculate the Bjerknes index are available from observations such as, for example, vertical velocities. Furthermore, some of the observational time series are only 20 years long and the time periods for which they are available only overlap for, in some cases, less than 10 years. For a dataset in which all variables are available and related to each other in a dynamically consistent way, we use output from the Nucleus for European Modeling of the Ocean (NEMO) global ocean circulation model with a horizontal resolution of $0.5^{\circ}$ (NEMO-ORCA05). The hindcast simulation used in this study is described in more detail in Lorbacher et al. (2010). NEMO-ORCA05 is forced by the interannually varying Co-ordinated Ocean-Ice Reference Experiments (CORE) (Griffies et al. 2009) atmospheric forcing for the time period 1958 to 2004. The surface boundary conditions for momentum, heat, and freshwater are implemented using a bulk forcing methodology. As a result, although no SST restoring is used, SST is implicitly damped toward the prescribed surface air temperatures and thus ceases to be a fully prognostic variable. Lübbecke and McPhaden (2012) showed that the model simulation successfully captures the interannual variability in the eastern equatorial Atlantic and Pacific. Observed and simulated time series of SST and SSH anomalies are highly correlated and agree in amplitude. Mechanisms that generate eastern equatorial SST anomalies including wind stress variations and equatorial wave propagation are well represented.

To assess the consistency of our results for different datasets we also use output from version 2.0.2-4 of the Simple Ocean Data Assimilation (SODA) ocean reanalysis product (Carton and Giese 2008) with a $0.5^{\circ}$ horizontal resolution and forced by surface momentum and heat fluxes from ERA-40. Monthly output is available for the time period 1958-2007. Fields from the same NEMOORCA05 and SODA simulations are used for calculating both Atlantic and Pacific stability index terms.

To calculate the BJ index, the coefficients introduced in Eq. (4) need to be determined from linear relations between two (or three) variables as, for example, between heat flux and SST anomalies to estimate the thermal damping $\alpha$. As in previous studies, we use linear least squares regression (LSR) that minimizes the sum of squared residuals between a dependent variable and the regression fit. To filter out high frequency fluctuations a 3-month running mean is applied to the time series prior to regression. The 3-month filter reduces scatter about the regression curves but does not significantly impact their slope. Error bounds for $95 \%$ confidence levels are determined by calculating the standard error of the regression slope and then multiplying it by the critical value according to a $t$ distribution with the degrees of freedom estimated from the decorrelation time scales of the time series. The decorrelation time scale is determined from the first zero-crossing of the autocorrelation function or, in case of no zero-crossing from using an $e$-folding scale determined by fitting an exponential to the autocorrelation function (Sarkar et al. 2002).

\section{BJ index calculation for the tropical Atlantic}

\section{a. Region}

Calculation of the individual terms of the $\mathrm{BJ}$ index is sensitive to the choice of region over which the variables are averaged. The volume average that is indicated by $\langle\cdot\rangle_{E}$ is here defined by the Atlantic 3 region (Atl3: $3^{\circ} \mathrm{S}-3^{\circ} \mathrm{N}, 20^{\circ} \mathrm{W}-0^{\circ}$ ) as the area of maximum interannual SST variability (Fig. 1b) and a mixed layer depth (MLD) of $32 \mathrm{~m}$, which is the mean MLD averaged over the Atl3 region in the NEMO-ORCA05 simulation. The MLD in the model is determined as the depth at which the density is $0.01 \mathrm{~kg} \mathrm{~m}^{-3}$ higher than at the surface.

The terms that are weighted by $L_{x}, L_{y}$, and $H_{m}$ are additionally dependent on the dimensions of the area and the effective depth of vertical advection. In our case, $L_{x}$ and $L_{y}$ are the zonal and meridional extent of the Atl 3 region, that is, $6^{\circ}$ latitude and $20^{\circ}$ longitude. The effective depth for vertical advection $H_{m}$ was found to be best represented as $43 \mathrm{~m}$. This is the depth of the first vertical NEMO-ORCA05 model level showing high vertical velocities in the Atl3 region. It also agrees with the relation between mixed layer depth and effective depth for vertical advection used in the Zebiak-Cane 

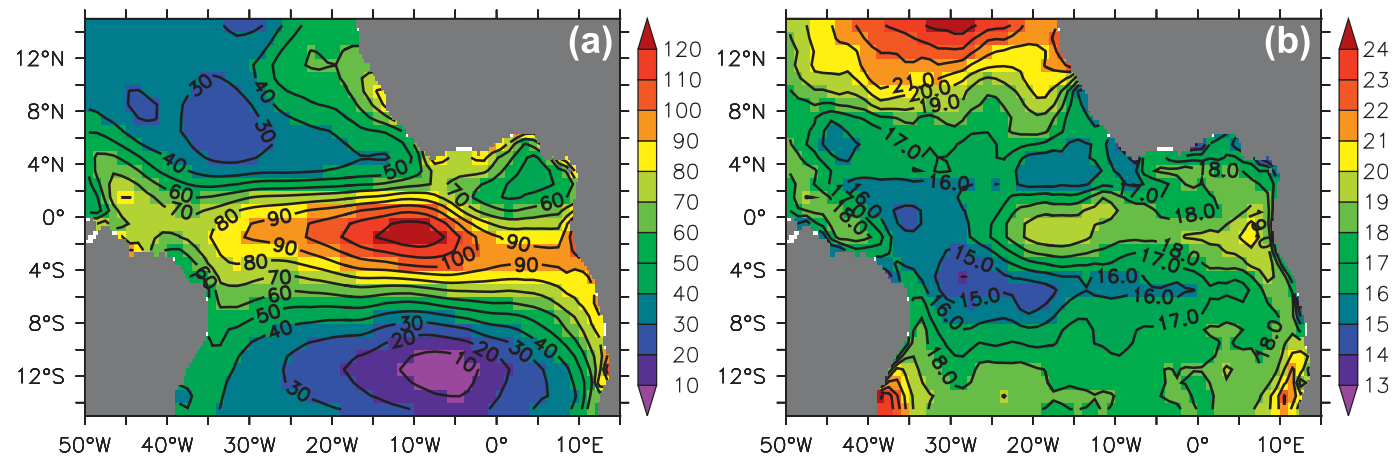

FIG. 2. (a) Mean net surface heat flux $\left(\mathrm{W} \mathrm{m}^{-2}\right)$ and (b) standard deviation of interannual heat flux anomalies in the tropical Atlantic from TropFlux (1979-2011).

model (Zebiak and Cane 1987). As explained by Stein et al. (2010), the difference between the mixed layer depth and the effective depth of vertical advection is due to the spatial inhomogeneities in upper ocean upwelling velocities in the cold tongue region. In the following section all terms contributing to the $\mathrm{BJ}$ index will be calculated and discussed.

\section{b. Thermal damping}

We start with the thermal damping term $\alpha$, which is determined from the relationship between interannual anomalies of net anomalous heat flux from the atmosphere into the ocean $Q$ and associated SST anomalies in the eastern equatorial Atlantic:

$$
\langle Q\rangle_{E}=\alpha\langle T\rangle_{E} .
$$

Fields of mean SST and net surface heat flux as well as their interannual variability are shown in Figs. 1 and 2. Mean net surface heat flux into the ocean is high over the cold tongue region, mainly due to reduced latent heat flux from the cool surface water. Interannual surface heat flux variability shows a local maximum in the cold tongue region (Fig. 2b), consistent with high interannual SST variability there (Fig. 1b). In a detailed analysis of mechanisms responsible for the heat flux feedback in the tropical Pacific, Lloyd et al. (2011) showed that shortwave and latent heat flux dominate.

The linear regression of Atl3 heat flux anomalies against Atl3 SST anomalies is shown in Fig. 3 for TropFlux heat flux and Reynolds SST (1982-2010), NEMO-ORCA05 (1958-2004), and ERA-40 heat flux and SODA SST (1958-2001). The correlation between heat flux and SST anomalies, all significant at the $95 \%$ level according to a Student's $t$ test, is highest in NEMOORCA05 $(r=0.64)$; it is lowest for TropFlux and Reynolds SST ( $r=0.47$ ), probably because the model SST is directly influenced by the model heat flux while the other datasets and reanalysis fields are more independent.
Differences also stem from the different time periods that were considered for the regression. The correlations are closer if the overlapping time period from 1982 to 2001 is considered for all three cases, namely 0.54 from NEMO-ORCA05, 0.55 from ERA-40/SODA, and 0.46 from Reynolds/TropFlux. The regression slope that represents the thermal damping $\alpha$ is fairly similar in all cases with the largest damping occurring for ERA-40/ SODA $\left(16.5 \pm 6.8 \mathrm{~W} \mathrm{~m}^{-2} \mathrm{~K}^{-1}\right)$, followed by $13.3 \pm$ $6.5 \mathrm{~W} \mathrm{~m}^{-2} \mathrm{~K}^{-1}$ for TropFlux/Reynolds and $12.4 \pm$ $3.8 \mathrm{~W} \mathrm{~m}^{-2} \mathrm{~K}^{-1}$ for NEMO-ORCA05. These values are in the range of other estimates for the heat flux feedback in the tropical Atlantic. Using SST and heat flux data from the Comprehensive Ocean-Atmosphere Data Set (COADS) and NCEP reanalysis, Frankignoul and Kestenare (2002) found a thermal damping of around $10-20 \mathrm{~W} \mathrm{~m}^{-2} \mathrm{~K}^{-1}$ for the eastern equatorial Atlantic. In a comparison between several coupled models (Frankignoul et al. 2004) the values ranged between 10 and $35 \mathrm{~W} \mathrm{~m}^{-2} \mathrm{~K}^{-1}$.

To compare the results for $\alpha$ to the other terms of the BJ index, they can be converted to a frequency by dividing them by the product of the mixed layer depth and the density and specific heat capacity of water. The corresponding thermal damping frequencies are then $1.52 \pm$ $0.7 \mathrm{yr}^{-1}$ for TropFlux/Reynolds, $1.42 \pm 0.43 \mathrm{yr}^{-1}$ for NEMO-ORCA05, and $1.88 \pm 0.8 \mathrm{yr}^{-1}$ for ERA-40/SODA.

\section{c. Dynamical damping}

The dynamical damping term

$$
-\left(\frac{\langle\bar{u}\rangle_{E}}{L_{x}}+\frac{\langle-2 y \bar{v}\rangle_{E}}{L_{y}^{2}}+\frac{\langle\bar{w}\rangle_{E}}{H_{m}}\right)
$$

consists of three terms for advection by mean zonal and meridional currents as well as mean upwelling at the base of the mixed layer. Assuming a warm SST anomaly in the eastern basin that is - in an anomaly sense - surrounded 

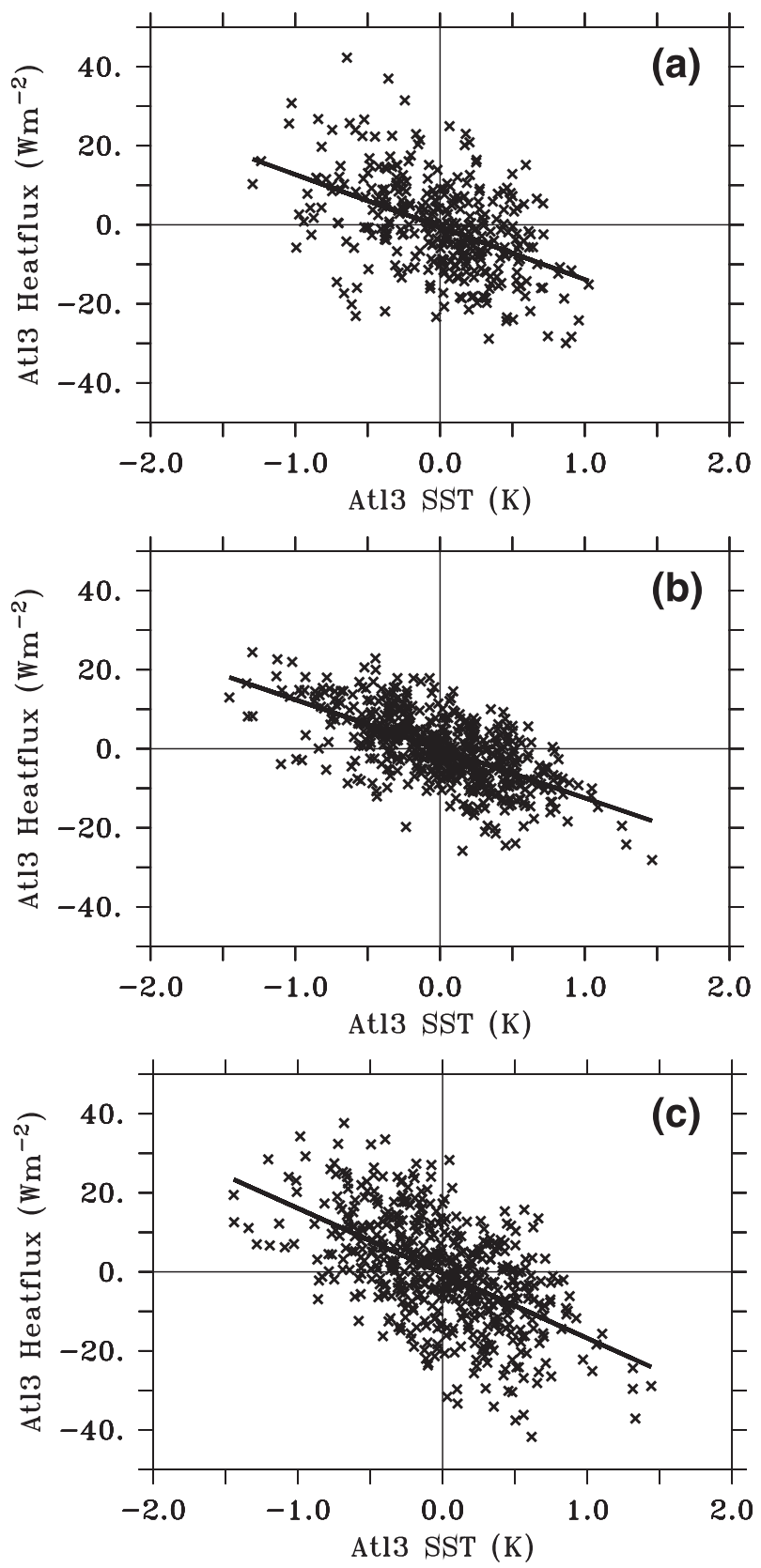

FIG. 3. Estimation of thermal damping $\alpha$ : linear regression between Atl3 SST and downward heat flux anomalies from (a) Reynolds SST vs TropFlux heat flux ( $r=0.47$, slope $=-13.3 \pm$ $\left.6.5 \mathrm{~W} \mathrm{~m}^{-2} \mathrm{~K}^{-1}\right)$, (b) NEMO-ORCA05 $(r=0.64$, slope $=-12.4 \pm$ $\left.3.8 \mathrm{~W} \mathrm{~m}^{-2} \mathrm{~K}^{-1}\right)$, and (c) SODA SST vs ERA-40 heat flux $(r=0.56$, slope $\left.=-16.5 \pm 6.8 \mathrm{~W} \mathrm{~m}^{-2} \mathrm{~K}^{-1}\right)$.

by cooler water, mean eastward zonal velocities would tend to damp this anomaly as would upward mean vertical velocities and mean meridional currents directed toward the center of the SST anomaly.

The mean upper-ocean flow field for the tropical Atlantic from the drifter climatology, OSCAR, NEMO-ORCA05, and SODA is shown in Fig. 4. It is dominated by the northward flowing North Brazil Current (NBC) crossing the equator along the western boundary and the westward flowing South Equatorial Current (SEC) centered at $4^{\circ}$ S. Surface drifter observations show mean westward velocities also in the eastern equatorial Atlantic (EEA), associated with the northern branch of the SEC [Fig. 4a, cf. Fig. 6 of Lumpkin and Garzoli (2005)]. The first term is thus positive $\left(3.38 \mathrm{yr}^{-1}\right)$; that is, it acts to enhance the SST anomaly. This is also the case in the NEMO-ORCA05 simulation (Fig. 4c) where we find a mean zonal advection contribution of $2.29 \pm 0.22 \mathrm{yr}^{-1}$. Zonal currents are rather weak but westward on average as well in the OSCAR data (Fig. 4b), leading to a mean zonal advection contribution of $0.41 \mathrm{yr}^{-1}$. In contrast, in SODA the Equatorial Undercurrent (EUC) extends all the way up to the surface so that eastward upper ocean velocities prevail in the EEA (Fig. 4d). The mean zonal advection term is thus negative for SODA $\left(-0.84 \pm 0.39 \mathrm{yr}^{-1}\right)$. Compared to velocity data from cross-equatorial ship sections and moored acoustic Doppler current profilers (ADCPs) at $23^{\circ} \mathrm{W}$ analyzed by Brandt et al. (2006), the depth of the EUC agrees very well in NEMO-ORCA05, while the upper boundary of the EUC is too shallow in SODA. This bias in SODA leads to unrealistic eastward velocities close to the surface. Regarding OSCAR currents, Helber et al. (2007) compared them to surface drifter and ship drift data for the tropical Atlantic and found that, despite a good overall agreement, OSCAR currents do not capture the strength of the SEC in the EEA, in particular in boreal winter and spring. We thus infer that the drifter and NEMO-ORCA05 results are more realistic.

The mean meridional velocity is more consistent among the different products but comparatively weak. Its contribution is further decreased by being more strongly weighted at the boundaries of the box than close to the equator. The second term is negative in all cases except for OSCAR and rather small $\left(-0.71 \mathrm{yr}^{-1}\right.$ from the drifter climatology, $0.31 \mathrm{yr}^{-1}$ from OSCAR, $-0.86 \pm 0.05 \mathrm{yr}^{-1}$ from NEMO-ORCA05, and $-0.85 \pm 0.07 \mathrm{yr}^{-1}$ from SODA).

There are no long-term observational datasets available for vertical velocity. We thus rely on the model simulations. The upwelling term has a value of $-1.69 \pm$ $0.15 \mathrm{yr}^{-1}$ from NEMO-ORCA05 and $-2.14 \pm 0.20 \mathrm{yr}^{-1}$ from SODA, that is, a strong damping effect in both cases. Together, the terms add up to a dynamical damping contribution of $-0.13 \pm 0.14 \mathrm{yr}^{-1}$ from NEMOORCA05 and $-1.92 \pm 0.22 \mathrm{yr}^{-1}$ from SODA. Thus, the dynamical damping is dominated by the upwelling term. In NEMO-ORCA05 it is much weaker than the thermal damping while it is of comparable size in SODA, owing to the unrealistically strong eastward upper zonal currents. 

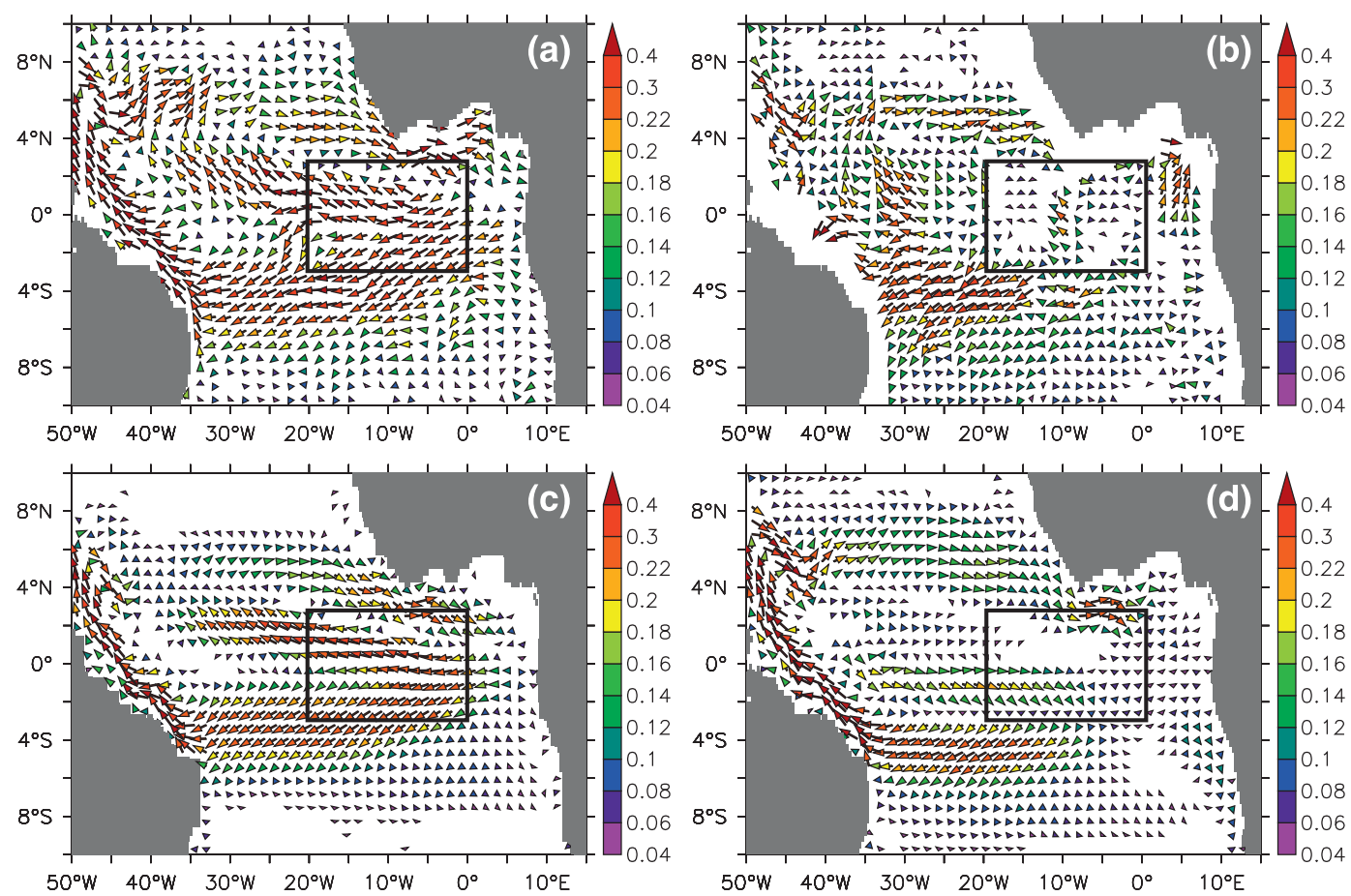

FIG. 4. Mean upper ocean currents $\left(\mathrm{m} \mathrm{s}^{-1}\right)$ in the tropical Atlantic from (a) drifter climatology, (b) OSCAR,

(c) NEMO-ORCA05, and (d) SODA; Atl3 region indicated by black box.

\section{d. Zonal advection feedback}

For all three positive feedback terms the parameter $\mu_{a}$ needs to be determined. It describes the response of the zonal component of equatorial wind stress to forcing by anomalous SST in the eastern equatorial basin. It multiplies the $\beta$ parameters in the various feedback terms to describe the effect of the anomalous zonal wind stress on ocean currents, upwelling, and thermocline slope. The parameter $\mu_{a}$ is estimated from the relationship between zonal wind stress anomalies averaged over the entire equatorial Atlantic $\left(3^{\circ} \mathrm{S}-3^{\circ} \mathrm{N}\right.$, $40^{\circ} \mathrm{W}-0^{\circ}$ ) and Atl3 SST anomalies; that is,

$$
\left[\tau_{x}\right]=\mu_{a}\langle T\rangle_{E} .
$$

The linear regressions are shown in Fig. 5 for Reynolds SST versus NCEP wind stress (1982-2010), NEMOORCA05 (1958-2004), and SODA (1958-2001). Correlations between SST and zonal wind stress anomalies are highest for NEMO-ORCA05 $(r=0.63)$ and a little lower for SODA and Reynolds/NECP ( $r=0.53$ and 0.50 , respectively). All correlations are significant at the $95 \%$ level according to a Student's $t$ test. The regression slope corresponding to $\mu_{a}$ is $0.48 \pm 0.22 \times$ $10^{-2} \mathrm{~N} \mathrm{~m}^{-2} \mathrm{~K}^{-1}$ for Reynolds SST and NCEP wind stress, very similar to the value calculated from SODA data $\left(0.47 \pm 0.19 \times 10^{-2} \mathrm{Nm}^{-2} \mathrm{~K}^{-1}\right)$. The slope is steeper for NEMO-ORCA05 with a value of $0.86 \pm 0.27 \times$ $10^{-2} \mathrm{~N} \mathrm{~m}^{-2} \mathrm{~K}^{-1}$. This value is close to that found by Keenlyside and Latif (2007) and Jansen et al. (2009) of about $0.75 \times 10^{-2} \mathrm{~N} \mathrm{~m}^{-2} \mathrm{~K}^{-1}$ between the Atl3 Hadley Centre Sea Ice and Sea Surface Temperature dataset (HadISST) and western Atlantic (WAtl) NCEP-NCAR wind stress anomalies for the period 1950-2002.

We note that Keenlyside and Latif (2007) and Jansen et al. (2009) used wind stress anomalies in the western half of the basin to define the relationship between zonal wind stress and SST because this is where the wind stress response to eastern equatorial SST anomalies is strongest. In the BJ index definition, however, dynamical consistency requires that the wind stress response to SST forcing is computed for the region that is used to estimate the ocean response to that wind stress forcing. Thus an average across the entire equatorial Atlantic is used for all parameter calculations as done in Kim and Jin (2011a). The sensitivity of our results to this choice is discussed in section 6 .

The zonal advection feedback term

$$
\mu_{a} \beta_{u}\left\langle-\frac{\partial \bar{T}}{\partial x}\right\rangle_{E}
$$

describes the effect on an eastern equatorial SST anomaly by wind-driven zonal currents acting on the mean zonal temperature gradient. Following Kim and 

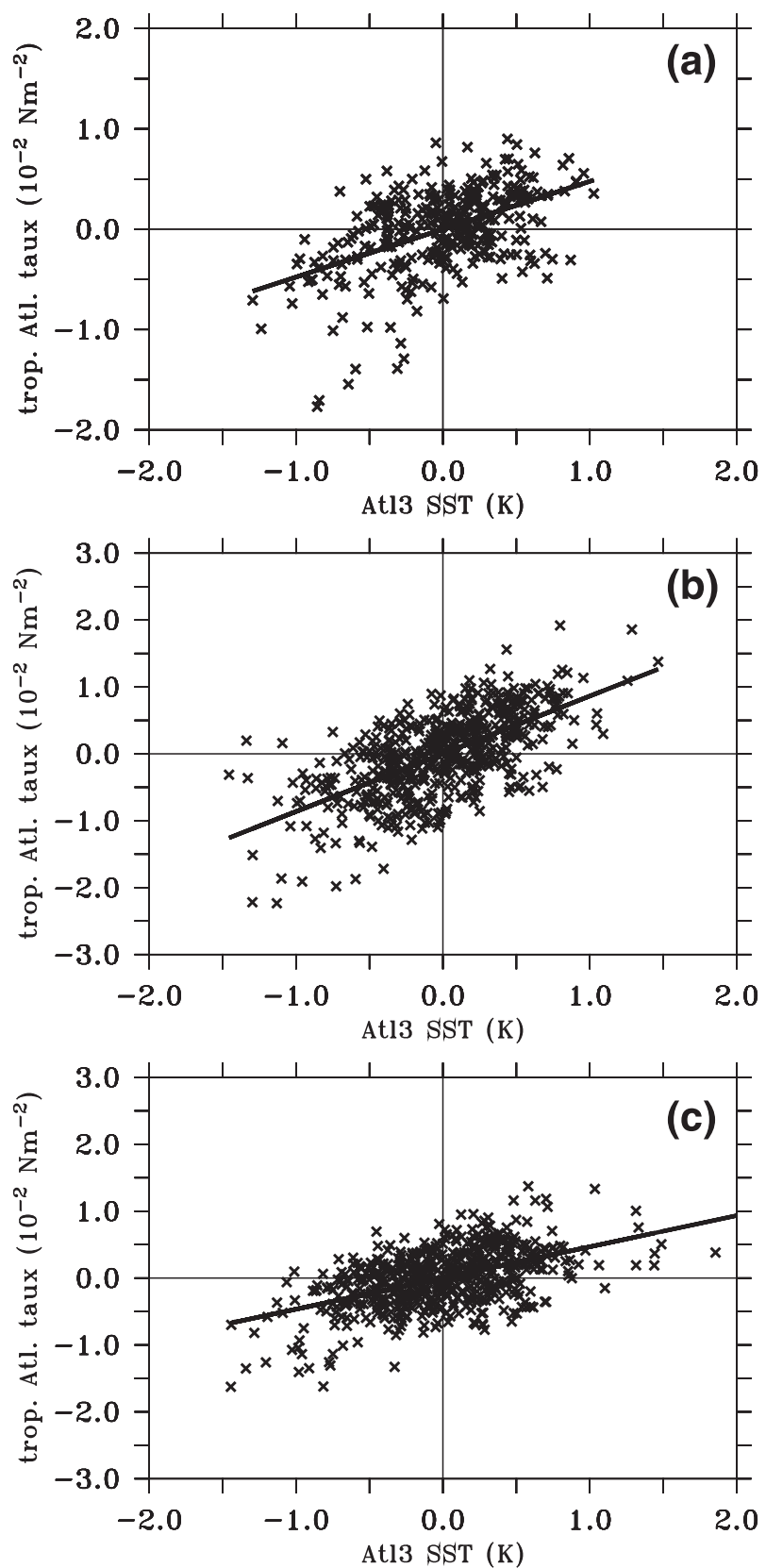

FIG. 5. Estimation of wind response to SST forcing $\mu_{a}$ : linear regression between Atl3 SST and equatorial Atlantic zonal wind stress anomalies from (a) NCEP wind stress and Reynolds SST ( $r=$ 0.50 , slope $=0.48 \pm 0.22 \times 10^{-2} \mathrm{~N} \mathrm{~m}^{-2} \mathrm{~K}^{-1}$ ), (b) NEMO-ORCA05 $\left(r=0.63\right.$, slope $\left.=0.86 \pm 0.27 \times 10^{-2} \mathrm{~N} \mathrm{~m}^{-2} \mathrm{~K}^{-1}\right)$, and (c) SODA $\left(r=0.53\right.$, slope $\left.=0.47 \pm 0.19 \times 10^{-2} \mathrm{~N} \mathrm{~m}^{-2} \mathrm{~K}^{-1}\right)$.

Jin, $\beta_{u}$ is estimated from an equation for near-surface zonal currents taking into account the effects of direct equatorial wind forcing and geostrophic adjustment to the thermocline depth gradient:

$$
\langle u\rangle_{E}=\beta_{u}\left[\tau_{x}\right]+\beta_{u h}\langle h\rangle_{W} .
$$

Then $\beta_{u}$ and $\beta_{u h}$ are calculated as the first and second multilinear regression coefficients between the Atl3 upper-layer zonal current anomalies and the zonal wind stress and the western Atlantic thermocline depth, respectively. Using OSCAR currents, TAOSTA thermocline depth, and NCEP wind stress anomalies for the overlapping time period of 1993-1999, we obtain values of $\beta_{u}=2.99 \pm 6.11 \mathrm{~m} \mathrm{~s}^{-1} \mathrm{~N}^{-1} \mathrm{~m}^{-2}$ and $\beta_{u h}=0.18 \times$ $10^{-2} \mathrm{~s}^{-1}$. The values are considerably larger for the model simulations with $\beta_{u}=7.92 \pm 1.55 \mathrm{~m} \mathrm{~s}^{-1} \mathrm{~N}^{-1} \mathrm{~m}^{-2}$ and $\beta_{u h}=0.43 \times 10^{-2} \mathrm{~s}^{-1}$ from NEMO-ORCA05 and $\beta_{u}=$ $18.76 \pm 6.04 \mathrm{~m} \mathrm{~s}^{-1} \mathrm{~N}^{-1} \mathrm{~m}^{-2}$ and $\beta_{u h}=1.3 \times 10^{-2} \mathrm{~s}^{-1}$ from SODA. Using $\beta_{u h}$ from the multilinear regression, Fig. 6 shows the linear regression between equatorial Atlantic zonal wind stress anomalies including the effect of geostrophic adjustment to thermocline depth changes and Atl3 zonal current anomalies. The correlation is quite high and significant at the 95\% level in NEMOORCA05 $(r=0.75)$ and in SODA $(r=0.63)$ whereas it is very low and not significant at the $90 \%$ level for the observational datasets $(r=0.18)$, reflected also in the very large uncertainty range for the observational data. This is probably related to the very short time period of overlapping years and the poor quality of the thermocline data [as pointed out by Keenlyside and Latif (2007)]. The $\beta_{u}$ value from the observational data can thus be deemed unreliable.

The zonal SST gradient averaged over the Atl3 region is $10.55 \times 10^{-8} \mathrm{~K} \mathrm{~m}^{-1}$ from Reynolds SST and $8.60 \times$ $10^{-8} \mathrm{~K} \mathrm{~m}^{-1}$ from NEMO-ORCA05 but only $2.53 \times$ $10^{-8} \mathrm{~K} \mathrm{~m}^{-1}$ from SODA. Thus, the total advective feedback term amounts to $0.02 \pm 0.04 \mathrm{yr}^{-1}$ from the observational data, $0.09 \pm 0.03 \mathrm{yr}^{-1}$ from NEMO-ORCA05, and $0.04 \pm 0.02 \mathrm{yr}^{-1}$ from SODA. Compared to the damping terms discussed above the zonal advective feedback is an order of magnitude smaller in all cases.

\section{e. Ekman feedback}

The Ekman feedback term

$$
\mu_{a} \beta_{w}\left\langle-\frac{\partial \bar{T}}{\partial z}\right\rangle_{E}
$$

describes the effect on an eastern equatorial SST anomaly by anomalous wind-forced upwelling acting on the mean vertical temperature gradient. The parameter $\mu_{a}$ characterizes the wind response to SST anomalies from Eq. (7), and $\beta_{w}$ is calculated from the relation between Atl3 upwelling and wind stress anomalies across the equatorial Atlantic:

$$
\langle H(\bar{w}) w\rangle_{E}=-\beta_{w}\left[\tau_{x}\right]
$$



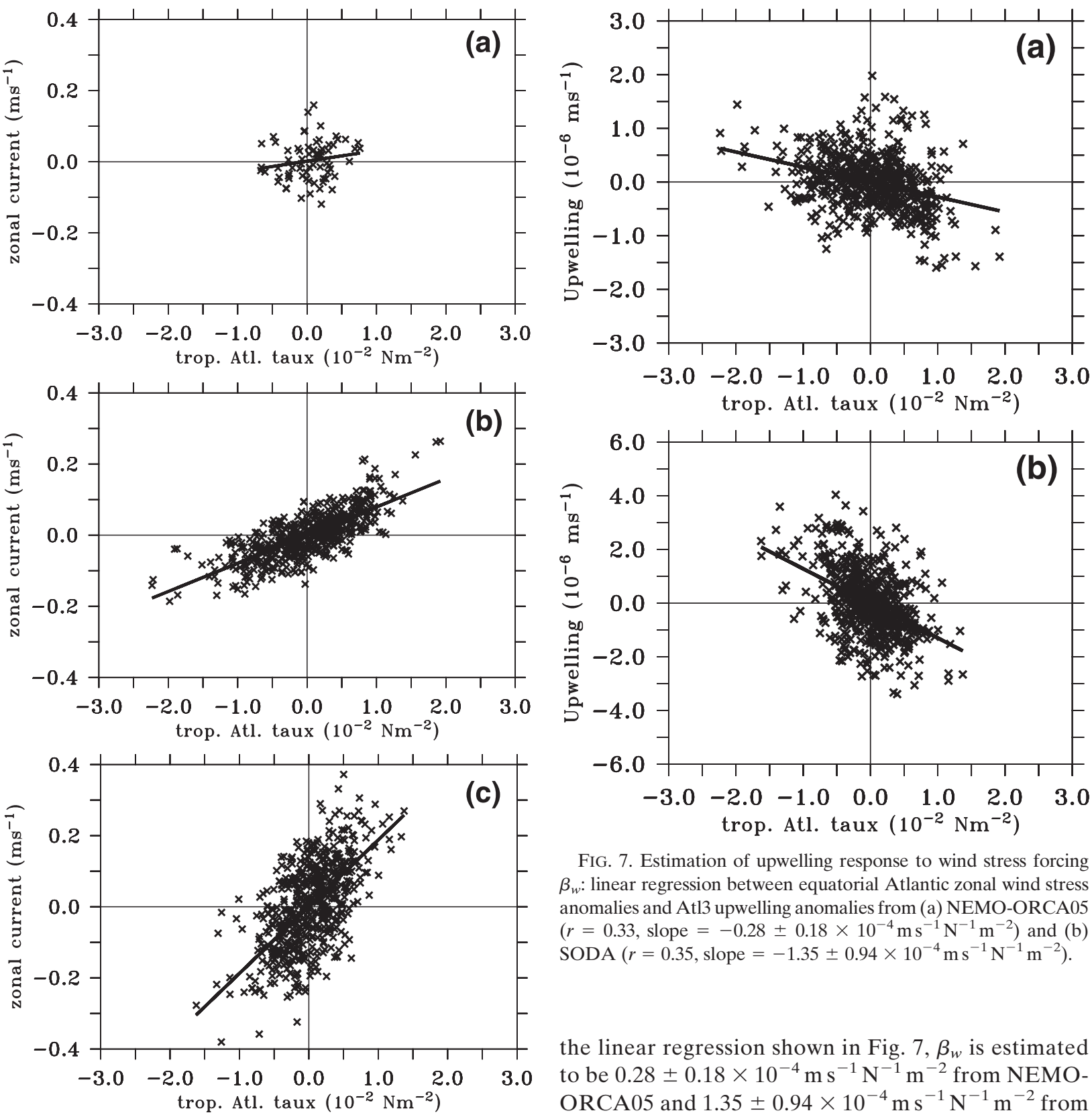

FIG. 6. Estimation of zonal current response to wind forcing $\beta_{u}$ : linear regression between equatorial Atlantic zonal wind stress anomalies plus geostrophic adjustment to thermocline depth changes and Atl3 zonal current anomalies from (a) OSCAR currents and NCEP wind stress $(r=0.18$, slope $=2.99 \pm$ $\left.6.11 \mathrm{~m} \mathrm{~s}^{-1} \mathrm{~N}^{-1} \mathrm{~m}^{-2}\right)$, (b) NEMO-ORCA05 $(r=0.75$, slope $=$ $\left.7.92 \pm 1.55 \mathrm{~m} \mathrm{~s}^{-1} \mathrm{~N}^{-1} \mathrm{~m}^{-2}\right)$, and (c) SODA $(r=0.63$, slope $=$ $18.76 \pm 6.04 \mathrm{~m} \mathrm{~s}^{-1} \mathrm{~N}^{-1} \mathrm{~m}^{-2}$ ).

The step function $H$ ensures that only upstream vertical advection is taken into account. Long-term observations of vertical velocities in the EEA are not available, so we have to rely on simulated upwelling time series. From

FIG. 7. Estimation of upwelling response to wind stress forcing $\beta_{w}$ : linear regression between equatorial Atlantic zonal wind stress anomalies and Atl3 upwelling anomalies from (a) NEMO-ORCA05 $\left(r=0.33\right.$, slope $\left.=-0.28 \pm 0.18 \times 10^{-4} \mathrm{~m} \mathrm{~s}^{-1} \mathrm{~N}^{-1} \mathrm{~m}^{-2}\right)$ and $(\mathrm{b})$ SODA $\left(r=0.35\right.$, slope $\left.=-1.35 \pm 0.94 \times 10^{-4} \mathrm{~m} \mathrm{~s}^{-1} \mathrm{~N}^{-1} \mathrm{~m}^{-2}\right)$.

the linear regression shown in Fig. 7, $\beta_{w}$ is estimated to be $0.28 \pm 0.18 \times 10^{-4} \mathrm{~m} \mathrm{~s}^{-1} \mathrm{~N}^{-1} \mathrm{~m}^{-2}$ from NEMOORCA05 and $1.35 \pm 0.94 \times 10^{-4} \mathrm{~m} \mathrm{~s}^{-1} \mathrm{~N}^{-1} \mathrm{~m}^{-2}$ from SODA. The correlation between upwelling and wind stress is rather low $(r=0.35$ for SODA, $r=0.33$ for NEMO-ORCA05, barely significant at the $90 \%$ level).

With an Atl3 vertical temperature gradient averaged over the upper layer of $-0.01 \mathrm{~K} \mathrm{~m}^{-1}$ (NEMO-ORCA05) and $-0.02 \mathrm{~K} \mathrm{~m}^{-1}$ (SODA), respectively, the Ekman feedback amounts to $0.04 \pm 0.03 \mathrm{yr}^{-1}$ from NEMOORCA05 and $0.20 \pm 0.16 \mathrm{yr}^{-1}$ from SODA. Thus, the Ekman feedback is more important than the zonal advection feedback in SODA but less in NEMO-ORCA05. In both cases it is small compared to the thermal damping term. 


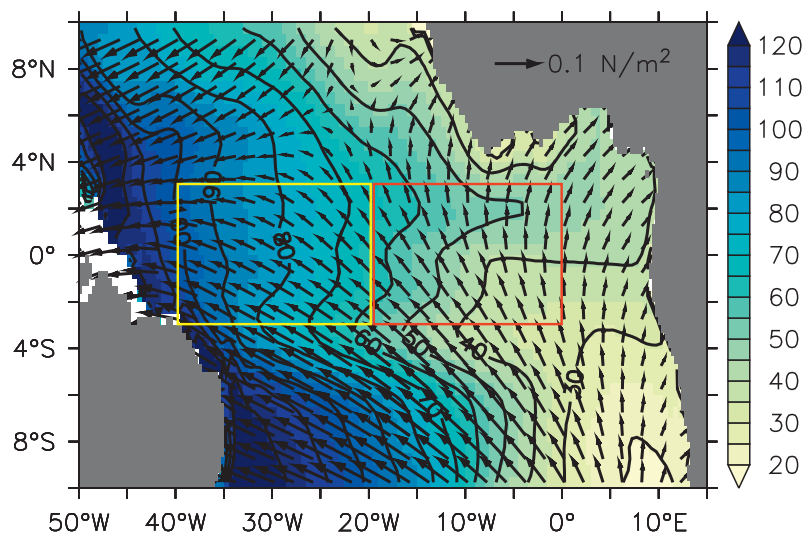

FIG. 8. Mean thermocline depth (as estimated by the depth of the $23^{\circ} \mathrm{C}$ isotherm) and wind stress in the tropical Atlantic from SODA; boxes indicate western (yellow: $3^{\circ} \mathrm{S}-3^{\circ} \mathrm{N}, 40^{\circ}-20^{\circ} \mathrm{W}$ ) and eastern (red: $\left.3^{\circ} \mathrm{S}-3^{\circ} \mathrm{N}, 20^{\circ} \mathrm{W}-0^{\circ}\right)$ averaging regions that are denoted by $\langle\cdot\rangle_{W}$ and $\langle\cdot\rangle_{E}$ in Eq. (10).

\section{f. Thermocline feedback}

The thermocline feedback term

$$
\mu_{a} \beta_{h}\left\langle\frac{H(\bar{w}) \bar{w}}{H_{m}} a_{h}\right\rangle_{E}
$$

reflects how wind-induced changes in the slope of the thermocline affect EEA subsurface and, subsequently, surface temperature. As shown in Fig. 8 the mean thermocline is deeper in the western tropical Atlantic than in the eastern part of the basin. This slope is due to the zonally integrated effect of mean easterly winds over the tropical Atlantic. Changes in zonal wind stress thus give rise to changes in the slope of the thermocline.

The coefficient $\beta_{h}$ is estimated from a relation for the adjustment of the thermocline slope to basinwide changes in zonal wind stress:

$$
\langle h\rangle_{E}-\langle h\rangle_{W}=\beta_{h}\left[\tau_{x}\right] .
$$

The linear regression fit for the difference between eastern and western equatorial Atlantic thermocline depth anomalies versus wind stress anomalies averaged across the equatorial Atlantic is shown in Fig. 9. Observational thermocline data are sparse, and thermocline slope anomalies from the XBT-derived TAOSTA dataset are only weakly related to NCEP zonal wind stress variations with a correlation of 0.19 , which is not significant at the $90 \%$ level. As pointed out by Keenlyside and Latif (2007), this is probably due to poor ocean subsurface temperature data quality. The data are thus not suited for reliably estimating $\beta_{h}$. Both SODA and NEMO-ORCA05 show a much stronger relationship between thermocline slope and zonal wind stress anomalies. The thermocline slope coefficient $\beta_{h}$ is found to be $11.5 \pm 1.9 \mathrm{~m}\left(10^{-2} \mathrm{~N} \mathrm{~m}^{-2}\right)^{-1}$
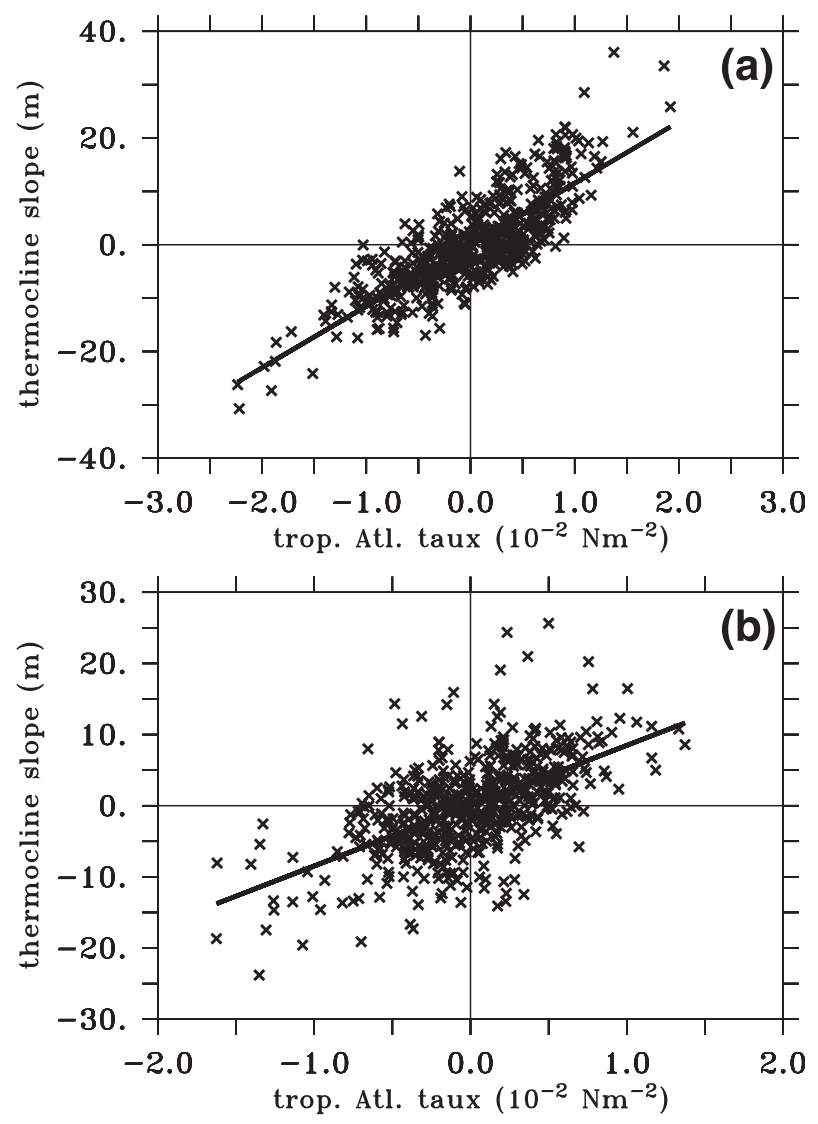

FIG. 9. Estimation of thermocline slope response to wind stress forcing $\beta_{h}$ : linear regression between eastern minus western thermocline depth anomalies and equatorial Atlantic zonal wind stress anomalies from (a) NEMO-ORCA05 $[r=0.81$, slope $=$

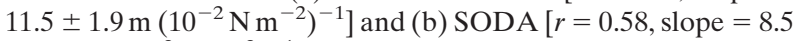
$\left.\pm 3.1 \mathrm{~m}\left(10^{-2} \mathrm{~N} \mathrm{~m}^{-2}\right)^{-1}\right]$.

for NEMO-ORCA05 $(r=0.81)$ and $8.5 \pm 3.1 \mathrm{~m}$ $\left(10^{-2} \mathrm{~N} \mathrm{~m}^{-2}\right)^{-1}$ for SODA $(r=0.58)$. Both correlations are significant at the $95 \%$ level.

Thermocline depth anomalies are associated with local subsurface temperature anomalies. Thus $a_{h}$ is estimated from the relationship

$$
\left\langle H(\bar{w}) T_{\text {sub }}\right\rangle_{E}=a_{h}\langle h\rangle_{E} .
$$

The regression slope in Fig. 10 is $3.8 \pm 0.9 \times 10^{-2} \mathrm{~K} \mathrm{~m}^{-1}$ for NEMO-ORCA05 and $6.9 \pm 10^{-2} \mathrm{~K} \mathrm{~m}^{-1}$ for SODA. The variables are highly correlated (both significant at the $95 \%$ level) at 0.78 and 0.88 , respectively.

Taking into account the values of $8.62 \pm 0.21 \times 10^{-8}$ and $8.77 \pm 0.22 \times 10^{-8} \mathrm{~s}^{-1}$, respectively, for mean upstream upwelling at the depth of the mixed layer that advects subsurface temperature anomalies to the surface, the thermocline feedback amounts to $0.51 \pm 0.22 \mathrm{yr}^{-1}$ for NEMO-ORCA05 and $0.38 \pm 0.21 \mathrm{yr}^{-1}$ for SODA. In 

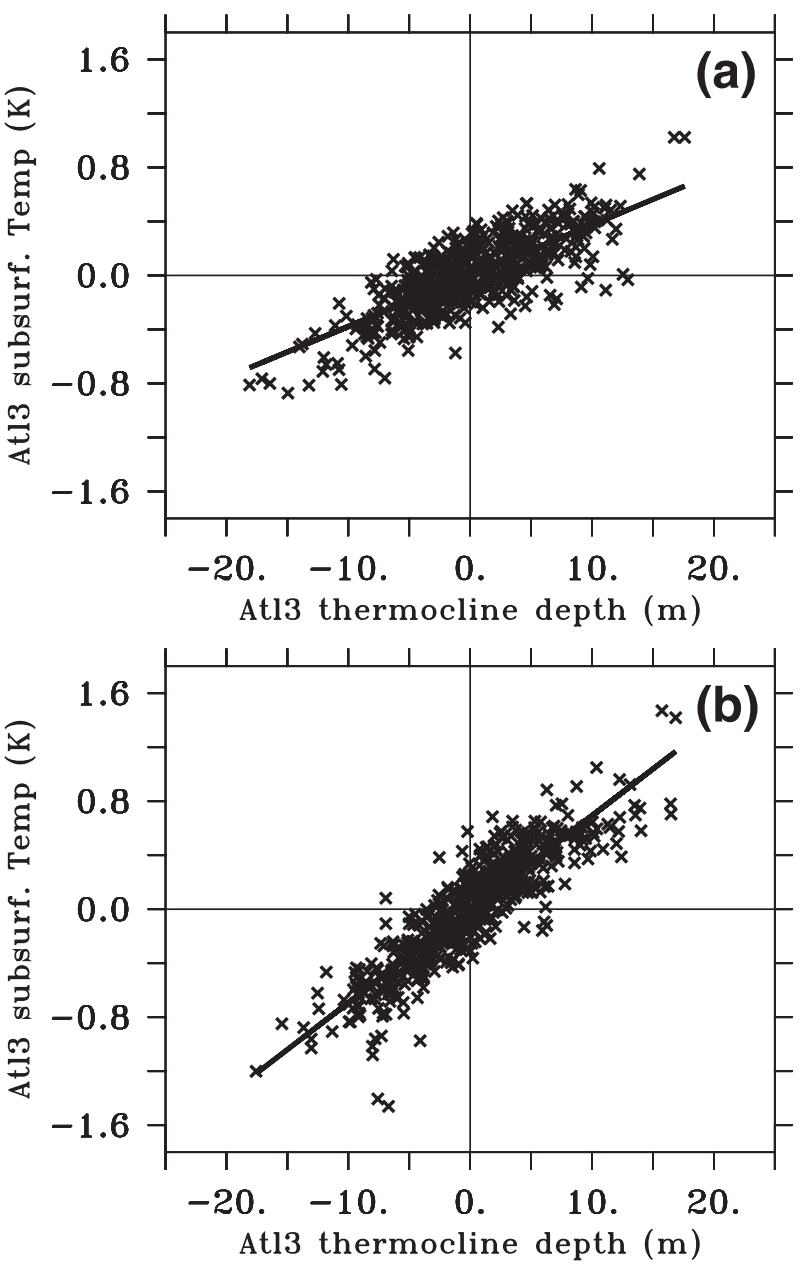

FIG. 10. Estimation of the effect thermocline depth changes have on ocean subsurface temperature $a_{h}$ : linear regression between Atl3 $T_{\text {sub }}$ and Atl3 thermocline depth anomalies from (a) NEMOORCA05 $\left(r=0.78\right.$, slope $\left.3.8 \pm 10^{-2} \mathrm{~K} \mathrm{~m}^{-1}\right)$ and (b) SODA $(r=$ 0.88 , slope $\left.6.9 \pm 10^{-2} \mathrm{~K} \mathrm{~m}^{-1}\right)$.

both cases, the thermocline feedback is the dominant positive feedback term.

\section{g. Total BJ index and comparison of individual terms}

Summing up all of the terms from the previous subsections gives a total $\mathrm{BJ}$ index of $-0.91 \pm 0.50 \mathrm{yr}^{-1}$ from NEMO-ORCA05 and $-3.19 \pm 0.85 \mathrm{yr}^{-1}$ from SODA. In both cases this corresponds to a damped system, with SODA much more strongly damped. Figure 11 illustrates the contributions of the individual components. In SODA, both damping terms are larger than any of the positive feedback terms. The largest negative contribution comes from the thermal damping in case of NEMO-ORCA05 while the dynamical damping is equally important in SODA. This difference is due to the upper-ocean eastward zonal velocities in SODA. On the positive side, the thermocline feedback is clearly the most important in both cases. In NEMO-ORCA05 both zonal advective and Ekman feedbacks are very small. In SODA, the Ekman feedback is half as strong as the thermocline feedback while the zonal advection feedback is negligible.

\section{Comparison with Pacific ENSO}

\section{a. Results from NEMO-ORCA05 and SODA}

To assess the differences between the Atlantic Niño mode and ENSO in the Pacific we compare the individual terms of our $\mathrm{BJ}$ index calculations for the Atlantic to results for the Pacific. There are a number of studies in which a Pacific BJ index has been calculated but to minimize the effect of model/dataset dependency and differences in the calculations, we compute a BJ index for the Pacific using output from the same NEMOORCA05 and SODA simulations as for the Atlantic. The results are shown in Fig. 11. Most of the terms including the total $\mathrm{BJ}$ index are in the range of previous studies for the Pacific (shown in Table 1).

The individual terms are calculated using the same methods as described for the Atlantic. For the averaging region, indicated by $\langle\cdot\rangle_{E}$, we choose the Niño-3 region $\left(5^{\circ} \mathrm{S}-5^{\circ} \mathrm{N}, 150^{\circ}-90^{\circ} \mathrm{W}\right)$ and the simulated mean mixed layer depth, averaged over that region, of $32 \mathrm{~m}$ using the same criterion as for the Atlantic. The linear regression between net surface downward heat flux and SST anomalies in this region gives a thermal damping of $\alpha=$ $13.9 \pm 3.1 \mathrm{~W} \mathrm{~m}^{-2} \mathrm{~K}^{-1}$ for NEMO-ORCA05 and $16.3 \pm$ $2.5 \mathrm{~W} \mathrm{~m}^{-2} \mathrm{~K}^{-1}$ for ERA-40/SODA, corresponding to a frequency of $1.6 \pm 0.4(1.9 \pm 0.3) \mathrm{yr}^{-1}$, similar to the results for the Atlantic. These values are somewhat lower than the ones found by Lloyd et al. (2011) for ERA-40 and OA Flux that are closer to $20 \mathrm{~W} \mathrm{~m}^{-2} \mathrm{~K}^{-1}$. The dynamical damping is dominated by the upwelling term as in the Atlantic and previous Pacific studies. In contrast to the SODA results for the Atlantic, the zonal velocities are westward in both cases in the eastern equatorial Pacific giving rise to an anomaly enhancing zonal current contribution. The meridional component is very weak. In total, the dynamical damping amounts to $-0.3 \pm 0.07 \mathrm{yr}^{-1}$ in NEMO-ORCA05 and $-0.5 \pm$ $0.08 \mathrm{yr}^{-1}$ in SODA.

The positive feedbacks are of similar magnitude in both cases as well. The smallest is the Ekman feedback, which amounts to $0.06 \pm 0.02 \mathrm{yr}^{-1}$ in NEMO-ORCA05 and $0.09 \pm 0.05 \mathrm{yr}^{-1}$ in SODA. The zonal advection feedback is roughly 3.5 times stronger with values of $0.22 \pm 0.06 \mathrm{yr}^{-1}$ in NEMO-ORCA05 and $0.33 \pm 0.12 \mathrm{yr}^{-1}$ in SODA. The comparatively large value in SODA is due to a large zonal SST gradient over the Niño-3 region, 

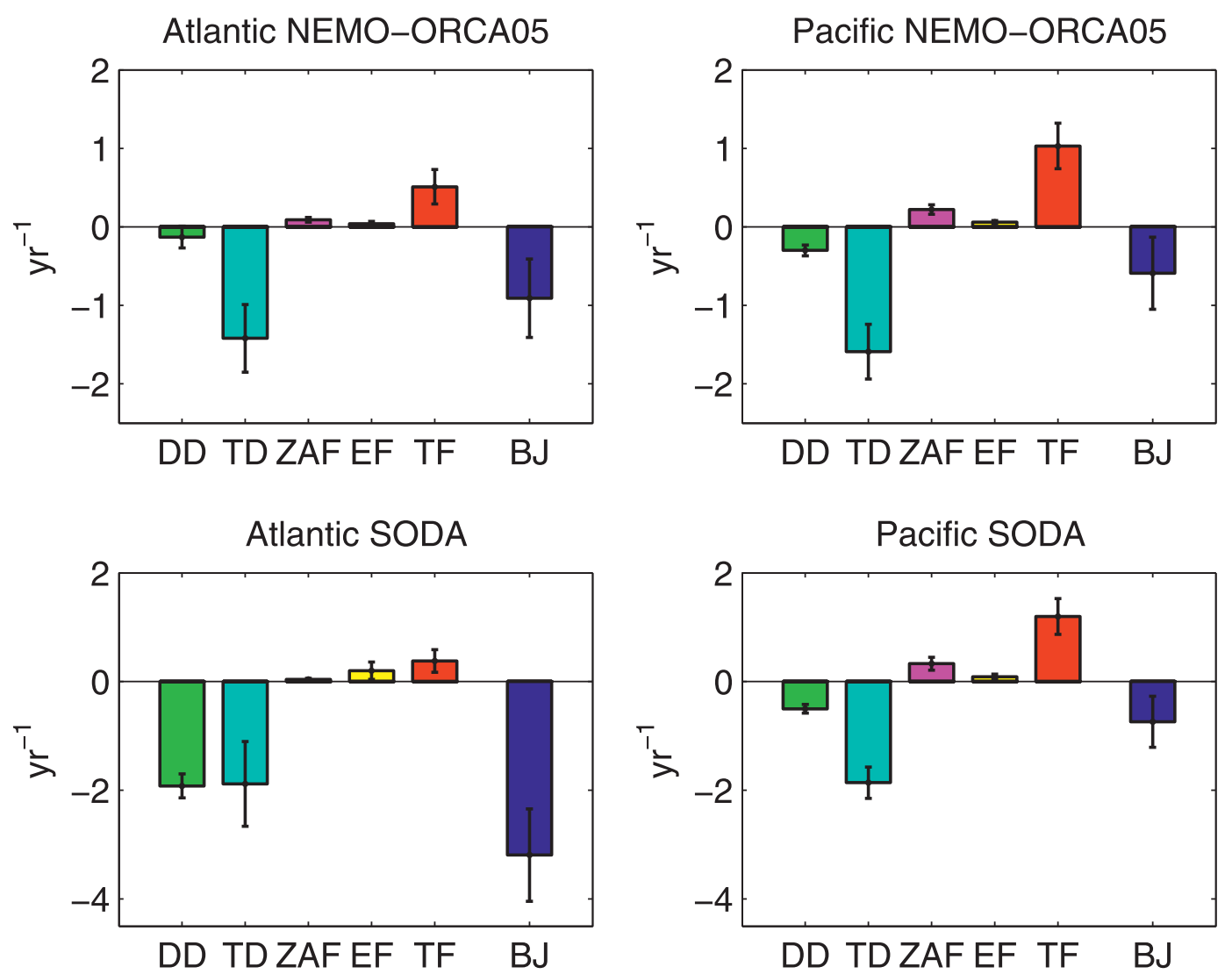

FIG. 11. Individual components of the BJ index from (top) NEMO-ORCA05 and (bottom) SODA, for the (left) Atlantic and (right) Pacific: dynamical damping (DD), thermal damping (TD), zonal advection feedback (ZAF), Ekman feedback (EF), thermocline feedback (TF), and BJ index (BJ). Note the different vertical scales for NEMOORCA05 and SODA.

while the zonal current response to wind forcing is similar to that in NEMO-ORCA05. In both cases the thermocline feedback is clearly the dominant positive feedbacks with values of $1.03 \pm 0.29 \mathrm{yr}^{-1}$ in NEMO-ORCA05 and $1.20 \pm 0.33 \mathrm{yr}^{-1}$ in SODA. The total BJ index amounts to $-0.59 \pm 0.46 \mathrm{yr}^{-1}$ in NEMO-ORCA05 and $-0.74 \pm$ $0.47 \mathrm{yr}^{-1}$ in SODA, that is, a damped system in both cases.
We note that the results for the Pacific for NEMOORCA05 and SODA are more similar than the corresponding Atlantic results. This points to the larger uncertainty associated with the Atlantic Niño mode. Comparing the Atlantic and Pacific results (Fig. 11) reveals that there are, however, robust basin to basin differences. Although the error bars overlap in NEMO-ORCA05 for the two basins, in both model and SODA reanalysis the

TABLE 1. Overview of results from previous studies and our results for the components of the Pacific $\mathrm{BJ}$ index $\left(\mathrm{yr}^{-1}\right)$ : dynamical damping (DD), thermal damping (TD), zonal advection feedback (ZAF), Ekman feedback (EF), thermocline feedback (TF), and total BJ index $\left(\mathrm{BJ}_{\text {total }}\right)$; note that these are approximate values inferred from figures in the cited studies.

\begin{tabular}{|c|c|c|c|c|c|c|}
\hline Study & DD & TD & $\mathrm{ZAF}$ & $\mathrm{EF}$ & $\mathrm{TF}$ & $\mathrm{BJ}_{\text {total }}$ \\
\hline NEMO-ORCA05 & -0.3 & -1.6 & 0.2 & 0.1 & 1.0 & -0.6 \\
\hline SODA & -0.5 & -1.9 & 0.3 & 0.1 & 1.2 & -0.8 \\
\hline Jin et al. (2006) & -1.5 & -1.5 & 0.3 & 0.1 & 2.8 & 0.2 \\
\hline Kim and Jin (2011a) & -0.5 & -1.3 & 0.6 & 0.9 & 1.7 & 1.4 \\
\hline Kim and Jin (2011b) SODA & -0.8 & -1.1 & 0.5 & 0.2 & 1.3 & 0.1 \\
\hline Kim and Jin (2011b) models & -0.5 to 1 & 0 to 1 & 0 to 0.3 & 0.2 to 0.5 & 0.2 to 1.5 & -2 to 1 \\
\hline Santoso et al. (2011) & -1.2 & -1.4 & 0.5 & 0.4 & 0.5 & -1.2 \\
\hline Stein et al. (2010) & -0.7 & -0.4 & 0.2 & 0.2 & 0.4 & -0.3 \\
\hline
\end{tabular}


total $\mathrm{BJ}$ index is more damped in the Atlantic than in the Pacific. Since thermal damping is the dominant negative feedback and of comparable size in both basins, we can attribute this difference mainly to the difference in the strength of the thermocline feedback. It is the dominant positive feedback in both basins and both NEMOORCA05 and SODA, though much stronger in the Pacific. In addition, the zonal advection feedback is about 2.5 times stronger in the Pacific than in the Atlantic in NEMO-ORCA05 and the difference is even larger in SODA. Thus, the cumulative effect is that the positive feedbacks are stronger in the Pacific than in the Atlantic. In SODA, the difference is further increased by the large dynamical damping in the Atlantic. Interestingly, the Ekman feedback in SODA is stronger in the Atlantic than in the Pacific due to a stronger upwelling response to wind forcing. Both zonal advective and Ekman feedback are, however, of secondary importance in the total index. The dominant thermocline feedback is twice as large in the Pacific compared to the Atlantic in NEMO-ORCA05 and about a factor of 3 larger in SODA.

Burls et al. (2012) found that the relationship between interannual anomalies of equatorial Atlantic available potential energy (APE), as a measure of the basinwide zonal thermocline slope, and Atl3 SST is considerably weaker than in the eastern equatorial Pacific. This suggests that differences in $a_{h}$ might be important. While the relation between thermocline slope and subsurface temperature is stronger in the Pacific $\left(3.8 \pm 0.9 \times 10^{-2} \mathrm{~K} \mathrm{~m}^{-1}\right.$ in the Atlantic versus $4.6 \pm 0.8 \times 10^{-2} \mathrm{~K} \mathrm{~m}^{-1}$ in the $\mathrm{Pa}$ cific in NEMO-ORCA05 and $6.9 \pm 0.6 \times 10^{-2} \mathrm{~K} \mathrm{~m}^{-1}$ in the Atlantic versus $7.5 \pm 0.6 \times 10^{-2} \mathrm{~K} \mathrm{~m}^{-1}$ in the Pacific in SODA), we find that a larger part of the difference stems from the stronger Pacific thermocline slope response to wind forcing. In the Pacific $\beta_{h}$ is twice as strong $\left[22.8 \pm 3.7 \mathrm{~m}\left(10^{-2} \mathrm{~N} \mathrm{~m}^{-2}\right)^{-1}\right]$ compared to the Atlantic $\left[11.5 \pm 1.9 \mathrm{~m}\left(10^{-2} \mathrm{~N} \mathrm{~m}^{-2}\right)^{-1}\right]$ in NEMO-ORCA05 and the difference is even slightly larger in SODA [21.1 \pm $3.8 \mathrm{~m}\left(10^{-2} \mathrm{~N} \mathrm{~m}^{-2}\right)^{-1}$ ] for the Pacific compared to $8.5 \pm$ $3.1 \mathrm{~m}\left(10^{-2} \mathrm{~N} \mathrm{~m}^{-2}\right)^{-1}$ for the Atlantic. This result is probably related to the fact that the thermocline response is proportional to the integral of the wind to the west of an observation point (Kessler and McPhaden 1995; Yu and McPhaden 1999) and the fetch of the zonal winds is much greater in the equatorial Pacific than in the equatorial Atlantic owing to the larger basin size.

\section{b. Results from previous studies}

Various authors have computed the BJ index to investigate different aspects of the Pacific ENSO mode. Here we will summarize these results and compare them to our calculations.
Stein et al. (2010) developed a seasonal stochastic recharge model to explore causes for the seasonal phaselocking of maximum ENSO SST anomalies to boreal winter. They used output from the high-resolution Ocean GCM for the Earth Simulator (OFES) in their analysis. On average, their BJ index turned out to be negative with a value of about $-0.3 \mathrm{yr}^{-1}$, that is, corresponding to a damped oscillator. The damping was dominated by the mean upwelling term reaching values of less than $-1 \mathrm{yr}^{-1}$. The thermal damping amounted to about $-0.4 \mathrm{yr}^{-1}$, which appears unrealistically weak compared to observations and reanalysis products (Lloyd et al. 2009). The positive feedback terms were in the range of $0.2 \mathrm{yr}^{-1}$ (zonal advection and Ekman feedback) to about $0.4 \mathrm{yr}^{-1}$ (thermocline feedback).

Kim and Jin (2011a) used a hybrid coupled model to study the effect of various ocean and atmosphere background states on ENSO stability. They found that on average the $\mathrm{BJ}$ index was positive $\left(1.4 \mathrm{yr}^{-1}\right)$ and dominated by the thermocline feedback. Depending on the background state, this feedback amounted to about $1.7 \mathrm{yr}^{-1}$ while the zonal advection and Ekman feedback terms were in the range of 0.6 and $0.9 \mathrm{yr}^{-1}$. Thermal damping dominated negative feedbacks and was about $-1.3 \mathrm{yr}^{-1}$.

In the study by Kim and Jin (2011b), the BJ index was adopted to assess the overall stability of ENSO in various coupled models from the coupled model intercomparison project CMIP3. They also used the ERA-40 atmosphere and SODA ocean reanalysis products to compute an "observed" BJ index. The results differ a lot between the different models with values for the BJ index ranging between -2 and $+1 \mathrm{yr}^{-1}$. The observed $\mathrm{BJ}$ index was calculated to $-0.24 \mathrm{yr}^{-1}$ with the thermal damping $\left(\sim-1.1 \mathrm{yr}^{-1}\right)$ and the thermocline feedback $\left(\sim+1.3 \mathrm{yr}^{-1}\right)$ dominating the negative and positive side, respectively. Most models showed a weaker mean zonal temperature gradient, mean upwelling, and atmospheric response to SST than the reanalysis data. Values ranged between -0.5 and $-1 \mathrm{yr}^{-1}$ for the dynamical damping, between approximately zero and $-1 \mathrm{yr}^{-1}$ for the thermodynamic damping, between approximately zero and $+0.3 \mathrm{yr}^{-1}$ for the zonal advection feedback, between approximately 0.2 and $1 \mathrm{yr}^{-1}$ for the Ekman feedback, and between 0.2 and $1.5 \mathrm{yr}^{-1}$ for the thermocline feedback.

Santoso et al. (2011) investigated the effect of a closed Indonesian Throughflow (ITF) on ENSO dynamics in a coupled model study. They found a negative BJ index for both the control run and the simulation with a closed ITF, the latter being more strongly damped. In the control run the $\mathrm{BJ}$ index was $-1.2 \mathrm{yr}^{-1}$ with thermal damping $\left(-1.4 \mathrm{yr}^{-1}\right)$ dominating negative feedbacks and the thermocline and Ekman feedback equally strong as positive feedbacks $\left(0.5 \mathrm{yr}^{-1}\right)$. 
The results from the different studies for the Pacific are summarized in Table 1. They exhibit a high degree of variability with $\mathrm{BJ}$ indices ranging from -2 to $+1.4 \mathrm{yr}^{-1}$. Most studies, however, agree that the thermocline feedback is the most important positive feedback mechanism, while the thermal damping is the dominant negative feedback, in agreement with our calculation of the Pacific BJ index from NEMO-ORCA05 and SODA. Also, most of the other terms and their relative importance, for example, upwelling dominating the dynamical damping, as well as the total BJ index from NEMOORCA05 and SODA, are in the range of previous studies. The thermal damping in both NEMO-ORCA05 and SODA is on the high end compared to previous studies. This might be partly related to the fact that most of the previous studies were based on output from coupled models. As noted by Lloyd et al. (2009), coupled models tend to have too weak heat flux feedbacks, mainly due to biases in the shortwave heat flux component (Lloyd et al. 2011). They found that coupled models showed weaker thermal feedbacks (with values between -3 and $-17 \mathrm{~W} \mathrm{~m}^{-2} \mathrm{~K}^{-1}$ ) in the Niño-3 region than what they found for ERA-40 and the Objectively Analyzed Air-Sea Fluxes (OAFlux) (-25.2 and $-20.8 \mathrm{~W} \mathrm{~m}^{-2} \mathrm{~K}^{-1}$, respectively).

\section{Summary and discussion}

In this study we have successfully applied the Bjerknes stability index to the Atlantic Niño mode. While differences between NEMO-ORCA05 and SODA are large, the results are consistent in that the Atlantic Niño mode is damped mainly due to strong thermal damping while the positive feedbacks are weaker. The dominant positive feedback is the thermocline feedback, while the Ekman feedback and zonal advection feedback play minor roles. Our results support the view that the Atlantic Niño mode is a damped system that needs external forcing from, for example, the Atlantic extratropics or the Pacific, to energize it.

The calculation of the individual BJ index terms gives an objective measure of the damping processes and feedbacks and their relative importance for the stability of the Atlantic Niño mode. Our results are thus a contribution to understanding the processes that control interannual SST variability in the tropical Atlantic, which is important with regard to their relation to rainfall variability over South America and western Africa.

Most coupled general circulation models show pronounced SST biases in the eastern tropical Atlantic and fail to simulate the observed interannual SST variability associated with the Atlantic Niño mode (e.g., Davey et al. 2002; Richter and Xie 2008). Knowing more about which feedbacks are strongest might be useful in order to address the problem of obtaining a more realistic representation of interannual SST variability in coupled models.

In comparison to ENSO in the Pacific, the Atlantic Niño mode is found to be more strongly damped mainly due to a weaker cumulative effect of the positive feedbacks while the negative thermal damping is of similar strength. Of particular interest in this respect is the strength of the thermocline feedback, which is the dominant positive feedback in both basins. While there are a number of uncertainties associated with the calculations, we find as a robust result that the thermocline slope response to anomalous wind forcing is much stronger in the Pacific, which is likely due to the longer wind fetch in the equatorial Pacific versus the equatorial Atlantic. The importance of the basin size for the strength of the Bjerknes feedback has been shown in theoretical studies finding a more unstable equatorial mode for a larger basin (Battisti and Hirst 1989).

While the dominance of the thermocline feedback and the thermal damping are robust, the quantitative results are associated with uncertainties as reflected in the error bars and the difference between the results from NEMO-ORCA05 and SODA. There is also a sensitivity to the averaging region, and previous studies have in some cases used different regions to quantify the feedback terms. As pointed out in section $4 \mathrm{~d}$, the BJ index formulation requires that the region used to compute the wind stress response to eastern equatorial SST anomalies $\mu_{a}$ is the same as the region that is then used to estimate the ocean response to that wind stress anomaly $\left(\beta_{u}, \beta_{w}\right.$, and $\beta_{h}$ ). We thus followed the approach by Kim and Jin (2011a) to use a basinwide zonal wind stress average for all parameters. Basin-scale winds have to be taken into account to reliably estimate the thermocline feedback, which is the dominant positive feedback. The zonal wind stress response to SST is, however, strongest in the western part of the basin so that calculating $\mu_{a}$ based on western basin average winds would result in larger values in both the Atlantic and Pacific. Using the western basin wind stress anomaly average would lead to smaller $\beta$ terms, however, because these terms capture the local eastern basin and basin-scale response. The overall effect on the positive feedback terms and, in turn, the total BJ index is thus rather small using western Pacific winds versus zonally averaged winds. An analogous compensation in the opposite direction occurs when the parameter calculation is based on an eastern basin average of zonal wind stress anomalies, as done for the Ekman and zonal advection feedback in the original $\mathrm{BJ}$ index formulation by Jin et al. (2006). In this case $\mu_{a}$ gets much smaller while $\beta_{u}$ and $\beta_{w}$ tend to be larger. 
While this somewhat reduces these two feedbacks, it does not significantly change the results.

We have shown that the $\mathrm{BJ}$ index can be used to assess the stability of the Atlantic Niño mode. It might thus serve as a useful tool to investigate various aspects of the Atlantic Niño as has been done for the Pacific ENSO, for example, differences between models, seasonal phase-locking, and the effect of different background states. Based on the large diversity in model results for the Pacific BJ index and the difference between our Atlantic results from NEMO-ORCA05 and SODA, different Atlantic models can be expected to show a lot of variability from one to another, but they will probably agree on the dominant role of thermal damping and thermocline feedback, as well as a damped total BJ index.

Acknowledgments. The authors would like to thank the anonymous reviewers for their comments. This research was performed while the first author held a National Research Council Research Associateship Award at NOAA/PMEL. We thank Simon Borlace for helpful advice on the calculations. The NEMO-ORCA05 simulation was performed at the Kiel University Computing Center and kindly provided by Arne Biastoch.

\section{REFERENCES}

Battisti, D. S., and A. C. Hirst, 1989: Interannual variability in the tropical atmosphere-ocean model: Influence of the basic state, ocean geometry and nonlinearity. J. Atmos. Sci., 46, 16871712.

Binet, D., B. Gobert, and L. Maloueki, 2001: El Niño-like warm events in the eastern Atlantic $\left(6^{\circ} \mathrm{N}\right.$ and $\left.20^{\circ} \mathrm{S}\right)$ and fish availability from Congo to Angola (1964-1999). Aquat. Living Resour., 14, 99-113.

Bjerknes, J., 1969: Atmospheric teleconnections from the equatorial Pacific. Mon. Wea. Rev., 97, 163-172.

Bonjean, F., and G. S. E. Lagerloef, 2002: Diagnostic model and analysis of the surface currents in the tropical Pacific Ocean. J. Phys. Oceanogr., 32, 2938-2954.

Brandt, P., F. A. Schott, C. Provost, A. Kartavtseff, V. Hormann, B. Bourlès, and J. Fischer, 2006: Circulation in the central equatorial Atlantic: Mean and intraseasonal to seasonal variability. Geophys. Res. Lett., 33, L07609, doi:10.1029/ 2005 GL025498.

_- and Coauthors, 2011: Equatorial upper-ocean dynamics and their interaction with the West African monsoon. Atmos. Sci. Lett., 12, 24-30, doi:10.1002/asl.287.

Burls, N., C. Reason, P. Penven, and G. Philander, 2012: Energetics of the tropical Atlantic zonal mode. J. Climate, 25, 7442-7466.

Carton, J. A., and B. Huang, 1994: Warm events in the tropical Atlantic. J. Phys. Oceanogr., 24, 888-903.

_ Simple Ocean Data Assimilation (SODA). Mon. Wea. Rev., 136, 2999-3017.

Chang, P., and Coauthors, 2006: Climate fluctuations of tropical coupled systems - The role of ocean dynamics. J. Climate, 19, $5122-5174$
Davey, M. K., and Coauthors, 2002: STOIC: A study of coupled model climatology and variability in tropical ocean regions. Climate Dyn., 18, 403-420.

Ding, H., N. S. Keenlyside, and M. Latif, 2010: Equatorial Atlantic interannual variability: Role of heat content. J. Geophys. Res., 115, C09020, doi:10.1029/2010JC006304.

Fedorov, A. V., and S. G. Philander, 2000: Is El Niño changing? Science, 288, 1997-2002.

Frankignoul, C., and E. Kestenare, 2002: The surface heat flux feedback. Part I: Estimates from observations in the Atlantic and North Pacific. Climate Dyn., 19, 633-647, doi:10.1007/ s00382-002-0252-x.

$\longrightarrow,-$ M. Botzet, A. F. Carril, H. Drange, A. Pardaens, L. Terray, and R. Sutton, 2004: An intercomparison between surface heat flux feedback in five coupled models, COADS and the NCEP reanalysis. Climate Dyn., 22, 373-388, doi:10.1007/s00382-003-0388-3.

Griffies, S. M., and Coauthors, 2009: Coordinated Ocean-Ice Reference Experiments (COREs). Ocean Modell., 26, 1-46.

Helber, R. W., E. S. Johnson, and G. S. E. Lagerloef, 2007: Satellitederived surface current divergence in relation to tropical Atlantic SST and wind. J. Phys. Oceanogr., 37, 1357-1375.

Illig, S., and B. Dewitte, 2006: Local coupled equatorial variability versus remote ENSO forcing in an intermediate coupled model of the tropical Atlantic. J. Climate, 19, 52275252.

Jansen, M. F., D. Dommenget, and N. S. Keenlyside, 2009: Tropical atmosphere-ocean interactions in a conceptual framework. J. Climate, 22, 550-567.

Jin, F.-F., 1997: An equatorial ocean recharge paradigm for ENSO. Part I: Conceptual model. J. Atmos. Sci., 54, 811-829.

_ - S. T. Kim, and L. Bejarano, 2006: A coupled-stability index for ENSO. Geophys. Res. Lett., 33, L23708, doi:10.1029/ 2006GL027221.

Kalney, E., and Coauthors, 1996: The NCEP/NCAR 40-Year Reanalysis Project. Bull. Amer. Meteor. Soc., 77, 437-471.

Keenlyside, N. S., and M. Latif, 2007: Understanding equatorial Atlantic interannual variability. J. Climate, 20, 131-142.

Kessler, W. S., and M. J. McPhaden, 1995: Oceanic equatorial waves and the 1991-93 El Niño. J. Climate, 8, 1757-1774.

Kim, S. T., and F.-F. Jin, 2011a: An ENSO stability analysis. Part I: Results from a hybrid coupled model. Climate Dyn., 36, 15931607, doi:10.1007/s00382-010-0796-0.

$\longrightarrow$, and — 2011b: An ENSO stability analysis. Part II: Results from the twentieth and twenty-first century simulation of the CMIP3 models. Climate Dyn., 36, 1609-1627, doi:10.1007/ s00382-010-0872-5.

Lloyd, J., E. Guilyardi, H. Weller, and J. Slingo, 2009: The role of atmosphere feedbacks during ENSO in the CMIP3 models. Atmos. Sci. Lett., 10, 170-176, doi:10.1002/asl.227.

- - - , and -2011 : The role of atmosphere feedbacks during ENSO in the CMIP3 models. Part II: Using AMIP runs to understand the heat flux feedback mechanisms. Climate Dyn., 37, 1271-1292, doi:10.1007/s00382-010-0895-y.

Lorbacher, K., J. Dengg, C. W. Böning, and A. Biastoch, 2010: Regional patterns of sea level change related to interannual variability and multidecadal trends in the Atlantic meridional overturning circulation. J. Climate, 23, 4243-4254.

Lübbecke, J. F., and M. J. McPhaden, 2012: On the inconsistent relationship between Pacific and Atlantic Niños. J. Climate, 25, 4294-4303.

Lumpkin, R., and S. L. Garzoli, 2005: Near-surface circulation in the tropical Atlantic Ocean. Deep-Sea Res. I, 52, 495-518. 
McPhaden, M. J., S. E. Zebiak, and M. H. Glantz, 2006: ENSO as an integrating concept in Earth science. Science, 314, 1740-1745.

Nobre, P., S. E. Zebiak, and B. P. Kirtman, 2003: Local and remote sources of tropical Atlantic variability as inferred from the results of a hybrid ocean-atmosphere coupled model. Geophys. Res. Lett., 30, 8008, doi:10.1029/2002GL015785.

Praveen Kumar, B., J. Vialard, M. Lengaigne, V. S. N. Murty, and M. J. McPhaden, 2012: TropFlux: Air-sea fluxes for the global tropical oceans-Description and evaluation. Climate Dyn., 38, 1521-1543, doi:10.1007/s00382-011-1115-0.

Reason, C. J. C., and M. Rouault, 2006: Sea surface temperature variability in the tropical southeast Atlantic Ocean and West African rainfall. Geophys. Res. Lett., 33, L21705, doi:10.1029/ 2006 GL027145.

Reynolds, R. W., N. A. Rayner, T. M. Smith, D. C. Stokes, and W. Wang, 2002: An improved in situ and satellite SST analysis for climate. J. Climate, 15, 1609-1625.

Richter, I., and S.-P. Xie, 2008: On the origin of equatorial Atlantic biases in coupled general circulation models. Climate Dyn., 31, 587-598, doi:10.1007/s00382-008-0364-z.

Santoso, A., W. Cai, M. H. England, and S. J. Phipps, 2011: The role of the Indonesian Throughflow on ENSO dynamics in a coupled climate model. J. Climate, 24, 585-601.
Sarachik, E. S., and M. A. Cane, 2010: The El Niño-Southern Oscillation Phenomenon. Cambridge University Press, 369 pp.

Sarkar, A., S. Basu, A. K. Varma, and J. Kshatriya, 2002: Autocorrelation analysis of ocean surface wind vectors. J. Earth Syst. Sci., 111, 297-303.

Stein, K., N. Schneider, A. Timmermann, and F.-F. Jin, 2010: Seasonal synchronization of ENSO events in a linear stochastic model. J. Climate, 23, 5629-5643.

Uppala, S. M., and Coauthors, 2005: The ERA-40 Re-Analysis. Quart. J. Roy. Meteor. Soc., 131, 2961-3012, doi:10.1256/qj.04.176.

Vauclair, F., and Y. du Penhoat, 2001: Interannual variability of the upper layer of the tropical Atlantic Ocean from in situ data between 1979 and 1999. Climate Dyn., 17, 527-546.

Xie, S.-P., and J. A. Carton, 2004: Tropical Atlantic variability: Patterns, mechanisms, and impacts. Earth Climate: The Ocean-Atmosphere Interaction, Geophys. Monogr., Vol. 147, Amer. Geophys. Union, 121-142.

Yu, X., and M. J. McPhaden, 1999: Seasonal variability in the equatorial Pacific. J. Phys. Oceanogr., 29, 925-947.

Zebiak, S. E., 1993: Air-sea interaction in the equatorial Atlantic region. J. Climate, 6, 1567-1586.

— , and M. A. Cane, 1987: A model El Niño-Southern Oscillation. Mon. Wea. Rev., 115, 2262-2278. 